\title{
(Im)possibilidade de reconstrução judicial da vontade de paciente relativamente incapaz, no âmbito de tratamentos médicos
}

\author{
(Im)possibility of judicial reconstruction of the relatively unable \\ patient's will, within the scope of medical treatments
}

\author{
Taisa Maria Macena de Lima ${ }^{1}$ \\ Manoel Antonio Silva Macedo ${ }^{2}$
}

\begin{abstract}
Resumo: O presente artigo busca oferecer uma resposta ao seguinte problema: é possível assegurar ao paciente, já na condição de incapaz, alguma forma de exercício do direito de decidir sobre cuidados e tratamentos que quer, ou não, receber? Foram estudados os aspectos mais relevantes da autonomia privada, no âmbito da relação médico-paciente, com apoio nos métodos científicos indutivo e dedutivo, por meio de pesquisa bibliográfica e documental. Atualmente, reconhece-se apenas aos pacientes lúcidos, ou aos que formalizaram diretivas antecipadas, o direito de decidir quais tratamentos médicos aceitam, ou não, receber. A hipótese aponta para a reconstrução judicial da vontade como alternativa que pode promover de maneira adequada o exercício da autonomia privada de pacientes incapazes, quando em situações de risco relevante à própria saúde. Ao final, conclui-se pela legitimidade da reconstrução judicial da vontade, com base em interpretação compatível com o tratamento legal conferido ao incapaz, que leva em consideração suas vontades e preferências.
\end{abstract}

Palavras-chave: Diretivas antecipadas. Incapacidade relativa. Autonomia privada. Reconstrução judicial de vontade.

\begin{abstract}
This article seeks to offer an answer to the following problem: is it possible to assure the patient, already in the condition of incapacity, some form of exercise of the right to decide on care and treatments that he
\end{abstract}

1 Doutora em Direito pela Universidade Federal de Minas Gerais (1990) e Mestre em Direito pela mesma Universidade (1985). Atualmente é professor adjunto IV da Pontifícia Universidade Católica de Minas Gerais e Desembargadora Federal do Trabalho - Justiça do Trabalho. Tem experiência na área de Direito, com ênfase em Teoria Geral do Direito, atuando principalmente nos seguintes temas: direitos de personalidade, responsabilidade civil, biodireito, interfaces do direito civil com o direito co trabalho, microssistemas no direito privado nacional.

2 Possui graduação em Direito concluída em 2000, pelas Faculdades Integradas de Vitória (FDV). Atualmente é Juiz de Direito titular da $4^{\text {a }}$ Vara Cível e Empresarial de Marabá Tribunal de Justiça do Estado do Pará. Mestre em Direito Privado pelo Programa de PósGraduação em Direito da Pontifícia Universidade Católica de Minas Gerais (PUC Minas), na Linha de Pesquisa: Reconstrução dos Paradigmas do Direito Privado no Contexto do Estado Democrático de Direito. Doutorando em Direito Privado pelo Programa de PósGraduação em Direito da Pontifícia Universidade Católica de Minas Gerais (PUC Minas), na Linha de Pesquisa: Novos Paradigmas, Sujeitos e Direitos. 
wants, or not, to receive, despite not having done advance directives? The most relevant aspects of private autonomy were studied, within the scope of the doctor-patient relationship, supported by scientific inductive and deductive methods, through bibliographic and documentary research. Currently, only lucid patients, or those who have formalized advance directives, before becoming incapable, are recognized the right to decide which medical treatments they accept, or not, to receive. The hypothesis points to the judicial reconstruction of the will as an alternative that can adequately promote the exercise of the private autonomy of disabled patients, when in situations of risk relevant to one's own health. In the end, it concludes by the legitimacy of the judicial reconstruction of the will, based on compatible interpretation with the legal treatment given to the person incapacitated, which takes into account her subjective wills and preferences.

Keywords: Advance directives. Relative disability. Private autonomy. Judicial reconstruction of will.

\section{Introdução}

Neste texto, parte-se do questionamento quanto à insuficiência de pensar numa autonomia privada projetada apenas para pacientes lúcidos, ou que dispuseram previamente sobre cuidados e tratamentos, em caso de incapacidade futura, nos termos da Resolução CFM n. 1.995/2012.

No cenário atual, indivíduos que perderam o discernimento, sem terem feito diretivas antecipadas, perdem a condição de igualdade com pessoas capazes, quanto à decisão sobre tratamentos médicos.

Com base nesse recorte, pretende-se analisar se é possível extrair alguma conclusão favorável à possibilidade de reconstrução judicial da vontade, a partir do direito de autodeterminação do paciente para escolha de tratamentos médicos, por meio de diretivas antecipadas, e da autonomia privada reconhecida para recusa terapêutica ${ }^{3}$.

Portanto, excluem-se do objeto deste estudo indivíduos sem condições de se expressar, nos termos do art. $4^{\circ}$, III, do Código Civil, já que para haver a reconstrução da vontade é necessário que, em algum momento, ela tenha existido e chegado ao conhecimento de outras pessoas.

\footnotetext{
${ }^{3}$ Art. 15 . Ninguém pode ser constrangido a submeter-se, com risco de vida, a tratamento médico ou a intervenção cirúrgica. (Código Civil).
} 


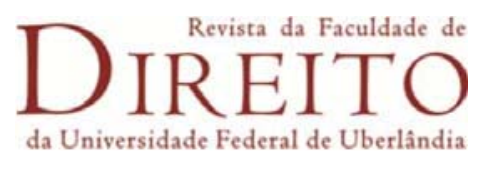

Ademais, em vista da complexidade do fenômeno referente ao direito de autodeterminação do paciente, a ausência de alternativas para lidar com situações de indivíduos, que não fizeram diretivas antecipadas, pode prolongar desnecessariamente o processo de morte, configurando, em alguns casos, a distanásia ${ }^{4}$.

Com a edição da Resolução CFM n. 2.232, de 17 de julho de 2019, mais indagações surgiram sobre a amplitude e legitimidade de restrições impostas ao direito de autodeterminação de pacientes, já que o médico passou a ter o dever ${ }^{5}$ de não aceitar a recusa terapêutica de menores de idade e de adultos, que não estejam no pleno uso de suas faculdades mentais, independente de haver representação ou assistência, em situações de risco relevante à coletividade, à saúde do enfermo ou de abuso de direito ${ }^{6}$.

São questionadas as razões usadas pelo dispositivo deontológico acima para se atribuir ao médico o poder de decidir o destino do paciente, fora das hipóteses que configuram abuso de direito, risco à saúde pública, ou que envolvam crianças e adolescentes.

Nesse contexto, em função do paternalismo médico de dispositivos deontológicos, sobressai a necessidade de analisar alternativas para se conferir ao paciente terminal, que esteja incapacitado, provisória ou permanentemente, de manifestar sua vontade, a chance de decidir o seu destino.

\footnotetext{
${ }^{4}$ Consiste na morte dolorosa decorrente de ações diagnósticas ou terapeuticas inúteis empreendidas por decisão do médico, ou em atendimento de pedido feito pelo paciente ou por seu representante legal. Tal prática é, expressamente, vedada pelo artigo 41, parágrafo único, do Código de Ética Médica. (CONSELHO FEDERAL DE MEDICINA, 2018).

5 Art. $3^{\circ}$ Em situações de risco relevante à saúde, o médico não deve aceitar a recusa terapêutica de paciente menor de idade ou de adulto que não esteja no pleno uso de suas faculdades mentais, independentemente de estarem representados ou assistidos por terceiros. (CONSELHO FEDERAL DE MEDICINA, 2019).

${ }^{6} \mathrm{Art} .5^{\circ} \mathrm{A}$ recusa terapêutica não deve ser aceita pelo médico quando caracterizar abuso de direito.

$\S 1^{\circ}$ Caracteriza abuso de direito:

I - A recusa terapêutica que coloque em risco a saúde de terceiros.

II - A recusa terapêutica ao tratamento de doença transmissível ou de qualquer outra condição semelhante que exponha a população a risco de contaminação. (CONSELHO FEDERAL DE MEDICINA, 2019).
} 


\section{Autonomia privada e direitos de personalidade}

Sobre o conceito de autonomia privada, Pietro Perlingieri ensina que ele depende em grande parte da configuração do ordenamento, mas que pode ser entendido, em geral, como o poder reconhecido pelo Estado a um indivíduo ou a um grupo de determinar vicissitudes jurídicas como consequências de seus comportamentos livremente assumidos (PERLINGIERI, 2002, p. 17).

Inicialmente, a concepção de autonomia privada era traduzida em regras jurídicas de relações mercantis, porém isso mudou radicalmente quando a liberdade da pessoa subordinou a si mesma a iniciativa econômica, de modo que as expressões de liberdade em matéria não-patrimonial passaram a ocupar uma posição mais elevada na hierarquia constitucional (PERLINGIERI, 2002, p. 17-18).

Com relação aos direitos de personalidade, Perlingieri diz que a cláusula geral de tutela da pessoa humana, tal qual se acha insculpida no artigo $1^{\circ}$, inciso III da Constituição brasileira, não se limita a resumir os direitos tipicamente previstos, porquanto a pessoa não se realiza através de um único esquema valorativo, assim como pode haver interesses mais decisivos e qualificados, além daqueles reconhecidos pelo ordenamento como direitos subjetivos e outras categorias moldadas para situações patrimoniais (PERLINGIERI, 2002, p. 154-156).

Por isso, tornou-se necessária a adoção de um conceito jurídico abrangente, a fim de exprimir os interesses qualificados pela complexidade normativa aplicável ao comportamento concreto, como o de situações jurídicas, criado pelo jurista Pietro Perlingieri (2002), em sua obra Perfis do direito civil.

Assim, chama-se de situação jurídica a categoria geral dos efeitos do agir humano, que encontra confirmação em princípios e normas legais, a 
exemplo de centros de interesses patrimoniais ou existenciais, que tenham ou não titulares (PERLINGIERI, 2002, p. 105).

Filiando-se à tese do jurista italiano, Rose Melo Vencelau Meireles (2009) ensina que a autonomia privada se apresenta para as situações jurídicas existenciais como verdadeiro instrumento de promoção da personalidade, visto que por meio do poder de autodeterminação garante-se a tutela das escolhas existenciais indispensáveis ao atendimento da dignidade humana.

\subsection{Autonomia privada existencial}

Em revisitação ao instituto da autonomia privada, Ana Carolina Brochado Teixeira sustenta que, apenas com a Constituição de 1988, a pessoa humana foi tutelada em sua totalidade, por meio de um catálogo aberto de direitos fundamentais, principalmente quando se trata de situações jurídicas existenciais, que não se resumem às questões de estado, capacidade e família, alcançando também os direitos de personalidade (TEIXEIRA, 2010, p. 127).

Segue-se daí que, para Teixeira, a autonomia privada nas situações existenciais não tem o mesmo caráter e tipologia da autonomia nas situações patrimoniais, nas quais o patrimônio ocupa a posição de bem jurídico central (TEIXEIRA, 2010, p. 138).

Tendo em vista tal diferença, a tutela negativa, conforme proteção típica das situações patrimoniais, tornou-se insuficiente, por se limitar ao momento patológico, que ocorre depois da lesão ou da desobediência a um dever geral de abstenção. Logo, em razão de a liberdade para realizar um contrato com fins patrimoniais não ser a mesma, qualitativamente falando, de uma situação jurídica existencial, foi necessário o desenvolvimento de outros tipos de proteção para a realização concreta da pessoa, que passou a 
desempenhar o papel de protagonista no Direito (TEIXEIRA, 2010, p. 127138).

Nesse tocante, Teixeira ensina que há uma diferença fundamental entre o modo de proteção das situações patrimoniais e existenciais, tendo como parâmetro as funções a serem realizadas: se patrimonial, a função repousa na livre iniciativa prevista no artigo 170 da Constituição Federal; se existencial, sua base está no princípio da dignidade da pessoa humana (art. $1^{\circ}$, III, Constituição Federal), de modo que tal diferença confere coerência e legitimidade aos argumentos usados para qualificar a situação jurídica e o correspondente regime jurídico aplicável (TEIXEIRA, 2010, p. 139-141).

Teixeira explica, ainda, que a autonomia privada existencial deve ser livre e expressa pelo próprio titular, mas que existem situações em que a própria pessoa pode instituir alguém para decidir por ela, em caso de incapacidade, ou mesmo de terminalidade, quando ainda estiver dotada de capacidade, cuja abrangência da decisão deve ser proporcional à sua aptidão de compreender e se expressar (TEIXEIRA, 2010, p. 162).

Apesar de considerar que a interferência do Estado na esfera jurídica existencial nega, de forma veemente, a autonomia e a responsabilidade, infantilizando o indivíduo, Teixeira conclui que a autonomia privada é limitada pelo espaço público democraticamente compartilhado entre todos, no qual são perseguidos interesses comuns, sob a lógica do princípio da liberdade (TEIXEIRA, 2010, p. 183).

Desse modo, a saúde pública constituiria um limite evidente à autonomia privada, pois no caso de a doença contagiosa representar uma ameaça social preponderaria o solidarismo, tendo em conta que o doente não pode acarretar dano a outrem, legitimando-se a intervenção para proteger os membros da coletividade (TEIXEIRA, 2010, p. 82-83).

Assim, conforme definição de Teixeira, a autonomia privada corresponde ao espaço de atuação da pessoa humana com eficácia normativa reconhecida pelo Estado, mas que é limitado pela convivência com o outro, 
no âmbito de uma mesma sociedade, reforçando a relevância da solidariedade (TEIXEIRA, 2010, p. 129).

Por essa razão, entende-se como legítima a restrição deontológica imposta na Resolução CFM n. 2.232/2019 com relação à não aceitação da recusa terapêutica, em situações de abuso de direito, de risco à saúde pública ou que envolvam crianças e adolescentes, em razão da necessária observância ao princípio da solidariedade, previsto no art. $3^{\circ}$, I, da Constituição Federal.

Entretanto, não se alcança a mesma conclusão quanto à não aceitação pelo médico, de forma absoluta, da manifestação de recusa terapêutica feita pelo representante legal do paciente adulto, que se tornou incapaz de expressar sua vontade.

Neste caso, ainda que seja possível invocar a incidência do princípio da solidariedade, no âmbito da esfera pessoal, é necessário atribuir um novo conteúdo que exprima alteridade, tolerância às escolhas individuais e dever de cooperação para o livre desenvolvimento da personalidade, sobretudo quando presente a vulnerabilidade ${ }^{7}$ justificadora de uma tutela mais intensa.

Atualmente, as situações de hipossuficiência ou vulnerabilidade se tornam cada vez mais frequentes, em face do aumento da expectativa de vida e do surgimento de diversos males degenerativos que acometem as pessoas, muitas das quais apenas sobrevivem, por longos períodos, ligadas a aparelhos e alimentadas por sondas, em estado de sofrimento.

Sá e Moureira argumentam que, na existência de quadros clínicos irreversíveis de pacientes, a vida transforma-se em verdadeiro dever de sofrimento, de modo que a antecipação da morte, além de atender aos

\footnotetext{
${ }^{7}$ Ana Carolina Brochado Teixeira afirma que, no âmbito familiar, essa proteção se dirige à criança, ao adolescente, ao idoso e ao deficiente, isso porque tais pessoas não têm condições sozinha de exercer sua subjetividade, sendo necessária a incidência do princípio da solidariedade. (TEIXEIRA, 2020, p. 121).
} 
interesses do paciente de ter um final digno, dá efetividade ao princípio da autodeterminação (SÁ; MOUREIRA, 2015, p. 10).

Além disso, não restam dúvidas que, com a edição da Res. CFM n. 1805, verificou-se a mudança do paradigma quantitativo da vida para o qualitativo $^{8}$, significando a aceitação da morte pelo paciente, no seu próprio tempo, sem medidas heroicas.

Nesse sentido, Sá e Moureira entendem que a discussão em torno de uma autonomia para morrer liga-se à possibilidade discursiva de o indivíduo exercer a liberdade no processo de construção de si mesmo, que pressupõe a busca pelo reconhecimento da sua pessoalidade ou da possibilidade de assumir uma identidade (SÁ; MOUREIRA, 2015, p. 10-12).

Assim, ante à necessidade de corrigir a fragilidade da pessoa vulnerável, assegurando o exercício das liberdades fundamentais, o Direito deve fornecer instrumentos jurídicos em observância ao princípio da igualdade material e da dignidade humana.

\subsection{Direitos de personalidade}

Os direitos de personalidade contêm os diversos aspectos da pessoa humana tutelados pelo ordenamento jurídico, como a vida, a intimidade, a integridade psicofísica, o nome, a honra, a imagem e todos os demais que exteriorizam o indivíduo no mundo.

Sá e Moureira afirmam que a fundamentação histórica dos direitos de personalidade é a mesma dos direitos fundamentais, pois foi no período posterior à Segunda Guerra mundial que eles passaram a ser assegurados nas Constituições dos Estados Democráticos. Por essa razão, os direitos de personalidade passaram a ser estudados, a partir de uma compreensão

\footnotetext{
8 Art. $1^{\circ}$ É permitido ao médico limitar ou suspender procedimentos e tratamentos que prolonguem a vida do doente em fase terminal, de enfermidade grave e incurável, respeitada a vontade da pessoa ou de seu representante legal. (CONSELHO FEDERAL DE MEDICINA, 2006).
} 
compartilhada com os direitos fundamentais, fortemente influenciada pelo princípio da dignidade da pessoa humana (SÁ; MOUREIRA, 2015, p. 48-49).

Contudo, a defesa e proteção da dignidade da pessoa humana e dos direitos de personalidade deve levar em conta a multiplicidade de valores nas sociedades plurais e democráticas, não havendo como, aprioristicamente, construir um substrato axiológico para se determinar uma concepção de vida boa, do contrário as pessoas não seriam tratadas como iguais.

Assim, do mesmo modo que há várias concepções de vida boa, existe uma diversidade de classificações oferecidas pelos juristas ${ }^{9}$ acerca dos direitos da personalidade, conquanto todas sejam convergentes em assegurar condições mínimas para que o indivíduo possa se desenvolver livremente no mundo exterior.

Um claro exemplo da pluralidade presente nos direitos de personalidade, que torna ilimitados os aspectos da pessoa humana, consiste na construção jurisprudencial recente feita pelo Supremo Tribunal Federal acerca do direito de personalidade à identidade de gênero (BRASIL, 2018).

Por outro lado, apesar de os direitos de personalidade serem avessos à taxatividade, a doutrina atribui características gerais, que os qualificam como: a) absolutos, no sentido de serem oponíveis erga omnes; b) necessários, pois essenciais à constituição e manutenção da dignidade da pessoa humana; c) vitalícios, pois acompanham a vida da pessoa; d) intransmissíveis, uma vez que permanecem com o titular até o fim de sua existência; e) irrenunciáveis, porque permanecem na esfera do titular, independentemente de sua vontade, f) extrapatrimoniais, por serem insuscetíveis de avaliação econômica; g) imprescritíveis, eis que não

\footnotetext{
9 Nesse sentido, DE CUPIS, 2004; GOMES, 1957; CHAVES, 1982; MIRANDA, 1954; AMARAL, 2000; FRANÇA, 1944 apud SÁ, Maria de Fátima Freire de; MOUREIRA, Diogo Luna. Autonomia para morrer: eutanásia, suicídio assistido, diretivas antecipadas de vontade e cuidados paliativos. 2. ed. Belo Horizonte: Del Rey, 2015, p. 60-62.
} 
desaparecem pelo não exercício; h) e impenhoráveis, ante a impossibilidade de sofrerem constrição judicial (SÁ; MOUREIRA, 2015, p. 63-65).

Entretanto, algumas dessas características, como a intransmissibilidade, precisam ser revistas, ante as transformações por que vem passando a sociedade contemporânea, em que indivíduos limitam ${ }^{10}$ voluntariamente o exercício de seus direitos de personalidade de imagem e intimidade, ao participarem de reality shows, ou como no caso de atletas, que licenciam a exploração comercial de sua imagem ${ }^{11}$.

Quanto ao exercício dos direitos de personalidade, há também que se fazer uma ressalva pertinente ao direito de saúde, consistente no fato de o mesmo se realizar de diversas formas, inclusive através da recusa terapêutica, e não apenas sob o enfoque da cura obstinada.

Nesse sentido, quando o indivíduo define diretivas ou manifesta a recusa terapêutica, não se pode falar em renúncia ao exercício dos direitos de personalidade, mas sim em ato de autonomia privada, que atenta para os valores eleitos para o livre desenvolvimento de sua personalidade.

Esse aspecto é enfatizado por Sá e Moureira, quando afirmam que a inviolabilidade do direito à vida contra arbitrariedades de terceiros não impede a construção da pessoalidade pelo titular. Assim, conquanto seja irrenunciável, persiste o caráter potestativo do direito de viver, cujo exercício pode ocorrer através da autonomia para morrer com dignidade, tanto por meio da recusa terapêutica, quanto pela elaboração de diretivas antecipadas (SÁ; MOUREIRA, 2015, p. 65).

\section{Diretivas antecipadas de vontade}

10 Art. 11. Com exceção dos casos previstos em lei, os direitos da personalidade são intransmissíveis e irrenunciáveis, não podendo o seu exercício sofrer limitação voluntária. (Código Civil).

${ }^{11}$ Art. 87-A. O direito ao uso da imagem do atleta pode ser por ele cedido ou explorado, mediante ajuste contratual de natureza civil e com fixação de direitos, deveres e condições inconfundíveis com o contrato especial de trabalho desportivo. (Lei n. 9.615, de 24 de março de 1998). 
As diretivas antecipadas de vontade surgiram como reflexo da atual relação médico-paciente, que tem como marco distintivo o protagonismo da pessoa na decisão sobre cuidados de saúde, mediante o consentimento livre e esclarecido.

Segundo Luciana Dadalto, as diretivas antecipadas constituem um gênero de manifestação de vontade para tratamento médico, do qual são espécies o testamento vital e o mandato duradouro. Ambos os documentos buscam assegurar a possibilidade de exercício da autonomia privada pelo enfermo, após se verificar eventual situação de incapacidade, permanente ou temporária, vinculando a atuação médica. No documento de testamento vital, o indíviduo estabelece os tratamentos que aceita ou não se submeter, já no mandato duradouro, o sujeito designa alguém para tal fim (DADALTO; TUPINAMBAS; GRECO, 2013).

Sá e Naves registram que o The Patient Self-Determination Act, em vigor nos Estados Unidos, desde 01/11/1991, foi o primeiro texto normativo a respaldar a autonomia prospectiva do paciente para estabelecer, por si só ou através de um representante nomeado, as intervenções médicas que aceita receber (SÁ; NAVES, 2018, p. 106-107).

No Brasil, em razão da ausência de legislação sobre o tema, o Conselho Federal de Medicina reconheceu, através da Resolução CFM n. 1995/2012, o direito de autodeterminação do paciente de fazer diretivas antecipadas (CONSELHO FEDERAL DE MEDICINA, 2012).

A Resolução CFM n. 1995/2012 estabelece, ainda, que o paciente poderá designar alguém para representá-lo na tomada de decisões sobre cuidados e tratamentos, e que as diretivas antecipadas de vontade podem ser diretamente comunicadas pelo paciente ao médico, a fim de que sejam registradas em prontuário, uma vez que não se exige forma prescrita. 
As diretivas também devem observar os preceitos éticos estabelecidos no Código de Ética, que vedam as práticas de eutanásia (art. 41) e de comércio de órgãos e tecidos humanos (art. 46).

Verifica-se, portanto, que a autonomia do paciente evoluiu de um caráter negativo de recusar tratamentos e cuidados médicos, devido à superação do modelo tradicional da relação médico-paciente, tendo por base a promoção da saúde além da existência biológica.

Interessante notar também que as diretivas antecipadas se relacionam com o princípio do livre desenvolvimento da personalidade, visto que por meio do poder de autodeterminação garante-se a tutela das escolhas existenciais indispensáveis à realização da dignidade humana.

Não fosse isso bastante, a adoção de uma concepção estritamente naturalística da vida como um bem absoluto e sagrado vai de encontro à disposição trazida pelo Código de Ética Médica, que prevê o dever médico de propiciar cuidados paliativos, nas situações clínicas irreversíveis e terminais (item XXII dos Princípios Fundamentais), muito além da preocupação com a mera existência físico-biológica.

No entanto, para os casos em que não são conhecidas diretivas antecipadas do paciente, ou não havendo familiares disponíveis ou consenso entre estes, a Resolução CFM n. 1995/2012 determina ao médico que recorra ao Comitê de Bioética da instituição, ou na falta deste, ao Conselho Regional ou Federal de Medicina, para fundamentar sua decisão sobre conflitos éticos.

Entende-se que, no lugar de procurar respostas para conflitos da relação médico-paciente em comitês bioéticos ou em órgãos de classe profissional, coloca-se a possibilidade de reconstruir a vontade do doente acerca de quais tratamentos desejaria receber, ou não, se tivesse tido a oportunidade de formalizar suas diretivas antecipadas.

Nessa perspectiva, indica-se a possibilidade de ouvir parentes, familiares e amigos próximos, que tenham convivência com o paciente, com 
fundamento na necessária efetivação da dignidade do ser humano, através do respeito à sua pessoalidade, no lugar de a decisão ser tomada por comitês bioéticos ou por conselhos profissionais, nos quais predomina a impessoalidade.

No entanto, objeta-se que meros indícios sejam suficientes para inferir que o sujeito concordaria com a realização da ortotanásia ou aplicação de cuidados paliativos, exigindo-se que tenha havido manifestação clara em tal sentido, e que a mesma tenha chegado ao conhecimento de terceiros.

Ademais, concorda-se com a ponderação feita por Gisele Mendes de Carvalho de que não se extrai da pretensão à morte digna um direito fundamental a dispor da própria vida, uma vez que muitas vezes o que o enfermo deseja é apenas a aplicação de medidas paliativas, que lhe proporcionem algum conforto, para que possa deixar de pensar na morte como única solução possível (CARVALHO In: ROMEO-CASABONA; SÁ, 2011, p. 164-165).

Este último argumento é decisivo para entender a compreensão de Teixeira e Sá sobre cuidados paliativos como tratamento integral que confere maior qualidade de vida à pessoa e para aqueles que compartilham do seu sofrimento, ainda que em outra dimensão, mesmo que isso implique em viver menos (TEIXEIRA; SÁ, 2018, p. 248).

\section{Reconstrução judicial da vontade}

Apesar da sua importância, as diretivas apenas orientam o agir médico, sem vincular juridicamente terceiros.

Todavia, em que pese o caráter classista da Resoluç,ão CFM n. 1995, ela ainda tem seu mérito por voltar os olhos da sociedade à discussão deste assunto de suma importância social, que justifica o amplo debate democrático (DADALTO; TUPINAMBAS; GRECO, 2013). 
Já a recusa para tratamentos ou intervenções tem previsão no art. 15 do Código Civil, com a diferença de que o paciente não tem afetada a sua capacidade civil, ao tempo da manifestação da vontade.

A tensão ocorre no caso de um indivíduo acometido de doença terminal, que recusa o tratamento disponível, mas é submetido ao mesmo pela decisão de algum familiar ou do próprio médico, no momento em que perde sua capacidade, sem ter feito diretivas antecipadas.

Além disso, na hipótese de conflito ético entre algum familiar e o médico quanto à realização ou não de tratamento, a Resolução n. 1995/2012 estabelece a competência do Comitê de Bioética da instituição, ou na falta deste, do Conselho Regional ou Federal de Medicina para dirimir o dissenso.

Não se olvide, ainda, que, conforme a Resolução CFM n. 2.232/2019, em situações de risco relevante à saúde, o médico possui o dever de não aceitar a recusa terapêutica de paciente adulto, que não esteja no pleno uso de suas faculdades mentais, o que também implica em situação de conflito ético.

Ora, se o indivíduo recusou quando capaz o tratamento médico, ciente de que tal escolha levaria ao curso natural do processo de morrer decorrente da doença, sua vontade deve ser considerada na decisão do conflito, não havendo que prevalecer o risco à saúde como argumento para a recusa médica, considerando, primeiro, que não se garante o sucesso do tratamento médico; segundo, o risco é inerente a qualquer cuidado de saúde; e, terceiro, o subjetivismo presente no conceito de risco relevante não concede o necessário espaço para autodeterminação do indivíduo vulnerável, que perdeu a capacidade de se expressar.

Por isso, a importância de perquirir as características pessoais, potencialidades, habilidades, vontades e preferências do incapaz, tal como se assegura no processo de interdição (art. 755, II, Código de Processo Civil) ${ }^{12}$.

${ }^{12}$ Art. 755. Na sentença que decretar a interdição, o juiz: 
Para isso ocorrer, o $\S 1^{\circ}$ do art. 755 do Código de Processo Civil estabelece ser necessário que a curatela decorrente da interdição seja atribuída a quem melhor possa atender aos interesses do curatelado.

O ordenamento jurídico busca, pois, garantir a maior participação do incapaz de praticar os atos da vida civil, quer seja por idade ou por enfermidade, conforme lembra Rose Melo Vencelau Meireles (2009), tal como fez o Estatuto da Criança e do Adolescente, que deu importância à vontade do menor de idade, conferindo-lhe o direito de liberdade de opinião e expressão, além de tornar indispensável o consentimento para o maior de 12 anos, mesmo na condição de absolutamente incapaz até os 16 anos incompletos, como requisito para a adoção.

Dessa forma, se há no ordenamento leis que determinam o respeito à vontade e aos interesses do incapaz, mediante a escolha de um representante que melhor possa atendê-los, entende-se que a única hipótese para admitir a solução de eventual conflito ético por comitês institucionais seria na ausência de qualquer pessoa que possa assumir tal função.

Entretanto, havendo mais de uma pessoa em condições de representar o incapaz, a escolha deve recair, necessariamente, em alguém que esteja comprometido em concretizar as vontades e preferências do paciente, sob pena de se transformar em letra morta o disposto no art. 755, II, do Código de Processo Civil. Para tanto, faz-se necessário reconstruir a vontade do paciente, a fim de verificar qual seria a sua decisão livremente manifestada sobre tratamentos e procedimentos médicos, com vistas a subsidiar a escolha da pessoa mais indicada para exercer tal múnus, sem ater-se à ordem de prelação prevista no Código Civil13.

II - considerará as características pessoais do interdito, observando suas potencialidades, habilidades, vontades e preferências. (Código de Processo Civi).

13 Art. 1.775. O cônjuge ou companheiro, não separado judicialmente ou de fato, é, de direito, curador do outro, quando interdito.

$\S 1^{\circ} \mathrm{Na}$ falta do cônjuge ou companheiro, é curador legítimo o pai ou a mãe; na falta destes, o descendente que se demonstrar mais apto.

$\S 2^{\circ}$ Entre os descendentes, os mais próximos precedem aos mais remotos.

$\S 3^{\circ} \mathrm{Na}$ falta das pessoas mencionadas neste artigo, compete ao juiz a escolha do curador. 
Neste particular, cita-se o paralelo encontrado no procedimento para o casamento nuncupativo ou in extremis, que, conforme ensinam Almeida e Rodrigues, dá-se quando algum dos contraentes, em iminente risco de morte, manifesta o desejo de casar-se com outra pessoa, na presença de seis testemunhas, não sendo possível o comparecimento da autoridade celebrante (art. 1.540 do CC). Após a celebração, as testemunhas devem comparecer perante a autoridade judicial mais próxima, dentro de dez dias, para ser tomada por termo a declaração do ocorrido, com subsequente registro no livro de Registro dos Casamentos (ALMEIDA; RODRIGUES JÚNIOR, 2012, p. 124).

Logo, entende-se que a lógica do procedimento previsto para o casamento nuncupativo, por ser referente a uma situação jurídica existencial, também é aplicável à ideia proposta de reconstrução judicial da vontade do enfermo incapaz quanto aos tratamentos, que quer, ou não, receber, visto que se baseia na mesma premissa.

Também na esfera patrimonial é possível reconstituir a vontade do indivíduo, com o testamento nuncupativo feito oralmente pelo militar, em combate, ou ferido, perante duas ou três testemunhas, nos termos do artigo $1.896^{14}$ do Código Civil.

Contudo, no âmbito médico, se houver dúvidas quanto à verdadeira vontade manifestada pelo doente quanto ao desejo de realizar ou não tratamentos, não há outra alternativa, senão observar o princípio in dubio pro vita, em função de prevalecer o princípio bioético da beneficência, inclusive para evitar a ação de pessoas mal-intencionadas (TEIXEIRA, 2010, p. 364).

Desse modo, a proposta hermenêutica que objetiva garantir respeito às preferências e vontades do paciente incapaz, em situações de conflito, através da reconstrução judicial da vontade, afigura-se estar em sintonia

\footnotetext{
14 Art. 1.896. As pessoas designadas no art. 1.893, estando empenhadas em combate, ou feridas, podem testar oralmente, confiando a sua última vontade a duas testemunhas.
} 
com os institutos jurídicos já existentes, bem como de acordo com tese de Ronald Dworkin, cujo traço fundamental é a defesa da virtude da integridade.

A teoria da integridade defendida por Dworkin entende que ninguém, pondo-se na condição de destinatário da decisão, aceitaria ser tratado como apenas mais um, no sentido de que todos nós temos o direito de sermos tratados com igual respeito e consideração pelo Judiciário, que deve levar cada caso a sério (PEDRON; OMMATI, 2020, p. 64-68).

Dworkin usa a figura de um juiz imaginário chamado Hércules, que é capaz de usar sua sabedoria e paciência para ponderar a busca da resposta correta para as suas sentenças. Hércules deverá levar em conta todos os argumentos trazidos pelas partes e a história institucional dos casos semelhantes decididos no passado, mas diferente dos juízes positivistas, não está preso ao passado, se verificar que há erros, sinalizando uma história em movimento, denominada romance em cadeia, ao qual poderá ser adicionado um novo capítulo coerente com o que já foi narrado, num sistema baseado em princípios jurídicos capazes de fornecer a melhor justificativa para os precedentes, leis e Constituição. A sentença de Hércules continuará sendo objeto de análise para confirmação ou refutação em casos futuros, de acordo com suas particularidades, percebendo-se aqui que a discricionariedade é eliminada para dar lugar a um esforço hermenêutico e argumentativo (PEDRON; OMMATI, 2020, p. 64-68).

Dessa maneira, o desafio posto é reconhecer a autonomia privada de pacientes para manifestar, em caso de doenças terminais e irreversíveis, a escolha pela ortotanásia ou por cuidados paliativos, que não pode ficar limitada à condição de deixar diretivas antecipadas, quando se sabe que não há forma prescrita no próprio dispositivo deontológico, e desde que o enfermo tenha livremente manifestado sua vontade perante terceiros.

Ademais, segundo Iara Antunes de Souza, o consentimento livre e esclarecido não tem forma determinada, admitindo-se a utilização de 
qualquer meio de prova abarcado pelo Direito, tais quais a confissão, documentos, testemunhas, presunção e perícia, nos termos do art. 212 do Código Civil (SOUZA, 2014, p. 24).

Assim, a sentença que declarar a vontade reconstruída do paciente incapaz constitui um capítulo coerente com os institutos jurídicos e deontológicos em vigor, mediante o contraditório e fundamentação dinâmicos, em virtude de conferir àquele que não fez diretivas antecipadas o mesmo tratamento igual e respeitoso assegurado ao capaz.

Lado outro, o dever de proporcionar um tratamento igual ao incapaz decorre, segundo Rose Melo Vencelau Meireles (2009), da conexão entre dignidade e liberdade, posto que mesmo aquelas pessoas, que tem o poder de autodeterminação limitado pela incapacidade civil, não deixam de ser consideradas merecedoras de tutela em sua dignidade.

Quanto ao respeito à história institucional, verifica-se que a ideia de assegurar igualdade ao paciente incapaz corresponde a um novo capítulo que se coaduna com o entendimento do STF acerca da liberdade de autodeterminação da pessoa humana, como resultado do contínuo empenho de melhorar a autonomia privada existencial de todos (BRASIL, 2012).

\subsection{Estudo de caso}

Considera-se importante trazer como ilustração do tema em análise um caso julgado pelo Tribunal de Justiça do Rio Grande do Sul acerca da vontade que buscou se reconstruir de uma paciente incapaz.

CONSTITUCIONAL. MANTENÇA ARTIFICIAL DE VIDA.
DIGNIDADE DA PESSOA HUMANA. PACIENTE,
ATUALMENTE, SEM CONDIÇÕES DE MANIFESTAR SUA
VONTADE. RESPEITO AO DESEJO ANTES MANIFESTADO.
Há de se dar valor ao enunciado constitucional da dignidade
humana, que, aliás, sobrepõe-se, até, aos textos normativos, seja
qual for sua hierarquia. O desejo de ter a "morte no seu tempo
certo", evitados sofrimentos inúteis, não pode ser ignorado,
notadamente em face de meros interesses econômicos atrelados a


eventual responsabilidade indenizatória. No caso dos autos, a vontade da paciente em não se submeter à hemodiálise, de resultados altamente duvidosos, afora o sofrimento que impõe, traduzida na declaração do filho, há de ser respeitada, notadamente quando a ela se contrapõe a já referida preocupação patrimonial da entidade hospitalar que, assim se colocando, não dispõe nem de legitimação, muito menos de interesse de agir. (RIO GRANDE DO SUL, 2011).

Na ementa, a demanda é tratada como a realização de ortotanásia de paciente acometida de séria doença e incapaz de expressar aos médicos sua vontade de não se submeter a hemodiálise.

O filho da paciente alegou perante o corpo médico que, antes de perder a consciência, ela teria manifestado a vontade de não realizar a hemodiálise, para evitar um sofrimento desnecessário.

Inobstante haver dúvida quanto à transmissão da vontade da paciente ao filho, o corpo médico poderia ter reconhecido a situação de terminalidade, evitando pôr em prática ações terapêuticas inúteis, nos termos do artigo 41, parágrafo único, do Código de Ética Médica, porém não houve manifestação clara em tal sentido.

Diante da irresignação do neto que insistia na manutenção dos tratamentos médicos, o impasse foi levado ao Judiciário pela entidade mantenedora do Hospital, através de ação cautelar de suprimento de vontade, objetivando que fosse nomeado o responsável legal para tomar a decisão de levar ou não a frente o tratamento médico indicado.

No decorrer do processo, pelo juízo de $1^{\circ}$ foi proferida grau sentença de indeferimento da petição inicial, por ilegitimidade ativa, seguida de apelação interposta pela parte autora, que sustentou sua legitimidade, frente à divergência familiar no tocante à aderência ou não da paciente ao tratamento proposto.

Apesar de ter sido o neto responsável pela internação da paciente, aquele teria manifestado vontade diversa e conflitante com a do filho, para quem, supostamente, teria sido transmitido o desejo de não receber $o$ tratamento médico. 
O acórdão reconheceu, à unanimidade, o dever de respeito ao desejo da paciente de não se submeter à hemodiálise, de resultados altamente duvidosos, negando provimento à apelação interposta pelo Hospital, por falta de interesse de agir.

Em seu voto, o Relator ponderou que o processo refletia a disputa entre a ortotanásia e a distanásia, bem como entendeu pela resolução do conflito, atribuindo a condição de responsável legal ao descendente mais próximo, no caso o filho, para quem, alegadamente, teria sido transmitida a vontade da paciente.

Contrário a esse entendimento, Sá e Naves argumentam que observar uma ordem de preferência, na impossibilidade de manifestação do paciente, impede a construção hermenêutica do caso concreto (SÁ; NAVES, 2018, p. 386).

Além disso, estabelecer que o descendente mais próximo responda pelo incapaz, como no julgado em análise, desconsidera, sobretudo nas hipóteses de conflitos familiares, a necessária construção de uma racionalidade quanto a quem melhor possa atender aos interesses da pessoa, observando características pessoais, potencialidades, habilidades, vontades e preferências.

Nesse sentido, defende-se a ideia de recorrer ao Judiciário, para reconstruir a vontade de paciente adulto terminal, já que mesmo a ausência de capacidade de fato não retira suas legítimas expectativas de viver com dignidade, encarando uma morte digna como parte desse processo.

\section{Conclusões}

A despeito de se entender que os dispositivos deontológicos em vigor asseguram espaços de autodeterminação ao paciente, verifica-se a existência de uma lacuna concernente à situação dos que não fizeram diretivas antecipadas. 
Assim, pensando numa resposta ao problema analisado, coloca-se como alternativa discursiva a reconstrução judicial da vontade do paciente adulto, que se tornou relativamente incapaz, de modo a permitir o respeito às suas vontades e preferências quanto ao recebimento, ou não, de tratamentos médicos, nos casos de doenças terminais.

No entanto, no caso de se entender pela aplicação da ortotanásia ou de cuidados paliativos, seria necessário, como precaução para se evitar a prática de abuso de direito, comprovar-se a ineficácia dos tratamentos médicos existentes.

Insiste-se na exigência de que o tratamento médico seja comprovadamente ineficaz para assegurar os interesses do paciente relativamente incapaz, na fase terminal de doenças graves e incuráveis, já que, na ausência de diretivas antecipadas, somente quando não houver eficácia da ação terapêutica pode-se falar em benefício ${ }^{15}$, em conformidade com a Resolução CFM n. 1.805/2006.

Pode-se dizer que o estudo fornece uma interpretação coerente para se pensar na reconstrução judicial da vontade daquele paciente, que não se valeu de diretivas antecipadas, tendo como referencial teórico a doutrina de Maria de Fátima Freire de Sá e Diogo Luna Moureira, com base na qual se afirma integrar o direito de morrer com dignidade ao exercício do próprio direito à vida, sem que se fale em renúncia (SÁ; MOUREIRA, 2015, p. 65).

Além do mais, claro está que o ordenamento jurídico já reconhece a possibilidade de reconstrução judicial da vontade para distintas situações jurídicas, com aplicação perfeitamente compatível aos conflitos éticos sobre a realização de tratamentos médicos.

Quanto aos depoimentos de testemunhas, se utilizado o procedimento previsto para o casamento nuncupativo, devem ser feitas algumas ressalvas, em razão dos interesses envolvidos, pois, na ausência de elementos

\footnotetext{
${ }^{15} \mathrm{O}$ benefício aqui mencionado corresponde ao princípio bioético da beneficência, que impõe ao profissional da saúde o dever de direcionar esforços para melhorar o estado do paciente.
} 
suficientes para se conhecer o desejo final do paciente, há que prevalecer o princípio do in dubio pro vita.

Portanto, conclui-se pela possibilidade hermenêutica de reconstruir a vontade do paciente adulto, que se tornou relativamente incapaz, com eficácia jurídica incidente sobre a relação médico-paciente, mediante o depoimento de testemunhas ou produção de outras provas em juízo, com a participação do Ministério Público, para que o doente não seja obrigado a submeter-se a um tratamento médico, que acarrete a soma de risco e sofrimento.

\section{Referências}

ALMEIDA, Renata Barbosa de; RODRIGUES JÚNIOR, Walsir Edson. Direito civil : famílias. - - 2. ed. - - São Paulo : Atlas, 2012.

BRASIL. Lei n. 9.434, de 4 de fevereiro de 1997. Dispõe sobre a remoção de órgãos, tecidos e partes do corpo humano para fins de transplante e tratamento e dá outras providências. Brasília, DF: Presidencia da República, [2007]. Disponível em: http://www.planalto.gov.br/ccivil_03/leis/L9434compilado.htm. Acesso em: 10 nov. 2020.

BRASIL. Supremo Tribunal Federal (Plenário). ADI 4275. Relator: Marco Aurélio. Relator p/ Acórdão: Edson Fachin, 1 mar. 2018. Diário de Justiça Eletrônico, Brasília, DF, n. 45, 7 mar. 2019.

http://redir.stf.jus.br/paginadorpub/paginador.jsp?docTP=TP\&docID=749297200. Acesso em: 4 nov. 2020.

BRASIL. Supremo Tribunal Federal (Plenário). ADPF 54. Relator: Min. Marco Aurélio, 12 abr. 2012. Diário de Justiça Eletrônico, Brasília, DF, n. 80, 30 abr. 2013. Disponível em: http://redir.stf.jus.br/paginadorpub/paginador.jsp?docTP=TP\&docID=3707334. Acesso em: 11 nov. 2020.

CARVALHO, Gisele Mendes de. Autonomia do paciente e decisões ao final da vida. In: ROMEO-CASABONA, Carlos María; SÁ, Maria de Fátima Freire de (Coord.). Direito biomédico: Brasil-Espanha. Belo Horizonte: Ed. PUC Minas, 2011.

CONSELHO FEDERAL DE MEDICINA (Brasil). Resolução CFM n. 1805/2006. Brasília, Diário Oficial da União, 28 nov. 2006, Seção I, p. 169. Disponível em: https://sistemas.cfm.org.br/normas/visualizar/resolucoes/BR/2006/1805. Acesso em: 7 nov. 2020.

CONSELHO FEDERAL DE MEDICINA (Brasil). Resolução CFM n. 1995/2012. Dispõe sobre as diretivas antecipadas de vontade dos pacientes. Brasília, Diário Oficial da União, 15 de dezembro de 2017, Seção I, p. 274-6. Disponível em: http://www.portalmedico.org.br/resolucoes/cfm/2012/1995_2012.pdf. Acesso em: 10 out. 2020.

CONSELHO FEDERAL DE MEDICINA (Brasil). Resolução CFM n. 2173/2017. Define os critérios do diagnóstico de morte encefálica. Brasília, Diário Oficial da União, 15 de dezembro de 2017, Seção I, p. 274-6. Disponível em: https://saude.rs.gov.br/upload/arquivos/carga20171205/19140504-resolucao-do-conselhofederal-de-medicina-2173-2017.pdf. Acesso em: 17 out. 2020. 


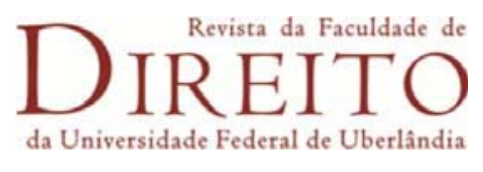

CONSELHO FEDERAL DE MEDICINA (Brasil). Código de Ética Médica: Resolução CFM n. 2.217, de 27 de setembro de 2018 , modificada pelas Resoluc,ões CFM n. 2.222/2018 e 2.226/2019. Brasília, Diário Oficial da União, $1^{\circ}$ de novembro de 2018, Seção I, p. 179. Disponível em: https://portal.cfm.org.br/images/PDF/cem2019.pdf. Acesso em: 10 jul. 2020.

CONSELHO FEDERAL DE MEDICINA (Brasil). Resolução CFM n. 2.232, de 17 de julho de 2019. Brasília, Diário Oficial da União, 17 set. 2019, Edição 179, seção I, p. 113. Disponível em: http://www.in.gov.br/en/web/dou/-/resolucao-n-2.232-de-17-de-julho-de-2019216318370. Acesso em: 17 out. 2020.

DADALTO, Luciana; TUPINAMBAS, Unai; GRECO, Dirceu Bartolomeu. Diretivas antecipadas de vontade: um modelo brasileiro. Rev. Bioét., Brasília, v. 21, n. 3, p. 463-476, dez. 2013. Disponível em: http://www.scielo.br/scielo.php?script=sci_arttext\&pid=S198380422013000300011\&lng=en\&nrm=iso. Acesso em: 22 fev. 2021

MEIRELES, Rose Melo Vencelau. Autonomia privada e dignidade humana. - Rio de Janeiro: Renovar, 2009.

PEDRON, Flávio Barbosa Quinaud; OMMATI, José Emílio Medauar. Teoria do direito contemporâneo: uma análise das teorias jurídicas de Robert Alexy, Ronald Dworkin, Jürgen Habermas, Klaus Günther e Robert Brandom. 2. ed. rev. e ampl. - Belo Horizonte: Conhecimento Editora, 2020.

PERLINGIERI, Pietro. Perfis do direito civil. Tradução de: Maria Cristina De Cicco. 3. ed., rev., e ampl. - Rio de Janeiro: Renovar, 2002.

RIO GRANDE DO SUL. Tribunal de Justiça do Rio Grande do Sul. Processo - AJALR n. 70042509562. Relator: Des. Arminio José Abreu Lima da Rosa. Porto Alegre, Diário da Justiça, 22 jun. 2011, Edição 4611. Disponível em: https://www1.tjrs.jus.br/site_php/consulta/consulta_processo.php?nome_comarca=Tribunal $\% 20 \mathrm{de} \% 20$ Justiça $\% 20 \mathrm{do} \% 20 \mathrm{RS} \& v e r s a 0=\& v e r s a o \_$fonetica $=1 \&$ tipo $=1 \& \mathrm{id}$ comarca $=700 \& \mathrm{nu}$ $\underline{m} \_$processo_mask $=\& n u m \_$processo $=70042509562 \& \operatorname{codEmenta}=7706337 \&$ temIntTeor $=$ true . Acesso em: 17 out. 2020.

SÁ, Maria de Fátima Freire de; MOUREIRA, Diogo Luna. Autonomia para morrer: eutanásia, suicídio assistido, diretivas antecipadas de vontade e cuidados paliativos. 2. ed. Belo Horizonte: Del Rey, 2015.

SÁ, Maria de Fátima Freire de; NAVES, Bruno Torquato de Oliveira. Bioética e biodireito. 4. ed. Belo Horizonte: Del Rey, 2018.

SÁ, Maria de Fátima Freire de (Org.) et al. Direito e medicina: autonomia e vulnerabilidade em ambiente hospitalar. São Paulo: Editora Foco, 2018.

SOUZA, Iara Antunes de. Aconselhamento genético e responsabilidade civil: as ações por concepção indevida (wrongful conception), nascimento indevido (wrongful birth) e vida indevida (wrongful life). - Belo Horizonte, 2014.

TEIXEIRA, Ana Carolina Brochado; SÁ, Maria de Fátima Freire de. Cuidados Paliativos: entre autonomia e solidariedade. Revista Novos Estudos Jurídicos - Eletrônica, Vol. 23, n. 1, jan-abr 2018. Disponível em: https://siaiap32.univali.br/seer/index.php/nej/article/view/13037. Acesso em: 19 set. 2020.

Artigo recebido em: 26/02/2021.

Aceito para publicação em: 10/08/2021. 